\title{
Surface roughness of zirconia for full-contour crowns after clinically simulated grinding and polishing
}

\author{
Rim Hmaidouch ${ }^{1}$, Wolf-Dieter Müller ${ }^{2}$, Hans-Christoph Lauer ${ }^{1}$ and Paul Weigl ${ }^{3}$
}

The aim of this study was to evaluate the effect of controlled intraoral grinding and polishing on the roughness of full-contour zirconia compared to classical veneered zirconia. Thirty bar-shaped zirconia specimens were fabricated and divided into two groups ( $n=15$ ). Fifteen specimens (group 1) were glazed and 15 specimens (group 2) were veneered with feldspathic ceramic and then glazed. Prior to grinding, maximum roughness depth $\left(\boldsymbol{R}_{\max }\right)$ values were measured using a profilometer, 5 times per specimen. Simulated clinical grinding and polishing were performed on the specimens under water coolant for $15 \mathrm{~s}$ and $2 \mathrm{~N}$ pressure. For grinding, NTI diamonds burs with grain sizes of $20 \mu \mathrm{m}, 10 \mu \mathrm{m}$, and $7.5 \mu \mathrm{m}$ were used sequentially. The ground surfaces were polished using NTI kits with coarse, medium and fine polishers. After each step, $\boldsymbol{R}_{\max }$ values were determined. Differences between groups were examined using one-way analysis of variance (ANOVA). The roughness of group 1 was significantly lower than that of group 2 . The roughness increased significantly after coarse grinding in both groups. The results after glazing were similar to those obtained after fine grinding for non-veneered zirconia. However, fine-ground veneered zirconia had significantly higher roughness than venerred, glazed zirconia. No significant difference was found between fine-polished and glazed zirconia, but after the fine polishing of veneered zirconia, the roughness was significantly higher than after glazing. It can be concluded that for full-contour zirconia, fewer defects and lower roughness values resulted after grinding and polishing compared to veneered zirconia. After polishing zirconia, lower roughness values were achieved compared to glazing; more interesting was that the grinding of glazed zirconia using the NTI three-step system could deliver smooth surfaces comparable to untreated glazed zirconia surfaces. International Journal of Oral Science (2014) 6, 241-246; doi:10.1038/ijos.2014.34; published 25 July 2014

Keywords: full-contour zirconia; grinding; polishing; roughness; veneering porcelain

\section{INTRODUCTION}

High-strength zirconium oxide was introduced for dental applications and is used as a core material that can be veneered with dental porcelain to customize the restoration in terms of form and aesthetics. The clinical use of this ceramic has continuously increased because of its high aesthetic potential, superior biocompatibility, chemical and dimensional stability, fracture toughness, hardness and frictional resistance compared to conventional dental ceramics. ${ }^{1-3}$ However, chipping of the veneering layer is the most commonly reported clinical complication for this type of all-ceramic restoration..$^{4-7}$

A possible solution for this problem is the industrial fabrication of mono-block restorations using computer aided design (CAD)/computer aided manufacturing (CAM) technology. ${ }^{8-9}$ These restorations could be fabricated from glass ceramics, but they are less stable compared to zirconia-based restorations, and their indication range is clearly limited to single crowns and small bridges. ${ }^{8-12}$ Therefore, zirconium oxide was suggested as an alternative to produce mono-block full-contour zirconia (FZ) restorations with occlusal designs that do not need to be veneered but only glazed. Consequently, the range of indications could be expanded, and the problem with chipping could also be eliminated. ${ }^{13}$
Glazing dental restorations produces a smooth, aesthetic and hygienic surface and is considered as a process that reduces the amount of wear of the opposing teeth; however, this layer of glaze will be removed shortly after insertion of the restorations or by any required adjustment. ${ }^{14}$ Thus, rough surfaces may result from chair-side modifications that necessitate adjusting occlusal contacts, refining cervical margins and reducing proximal contours to provide interproximal contact areas. Rough restoration surfaces are associated with aesthetic, caries or periodontal problems. In addition, roughened occlusal surfaces of ceramic restorations can lead to increased wear of the opposing teeth. Therefore, there is general agreement among dentists that roughened ceramic surfaces must be polished to prevent or at least minimize rapid wear of the opposing teeth, ${ }^{15-16}$ as well as to enhance aesthetics and restoration longevity, by removing the defects produced after surface grinding. ${ }^{2,17-18}$ Furthermore, smooth surfaces reduce plaque accumulation and the retention of bacteria. ${ }^{19-21}$

Chair-side polishing of all-ceramic restorations is efficient, easy for the clinician and eliminates repeated laboratory procedures. However, because the final occlusal adjustments of dental restorations have to be made after cementation, there is always a need for careful intra-oral polishing of the ground surfaces. Some investigations have been made

${ }^{1}$ Department of Prosthodontics and Geriatric Dentistry, Faculty of Oral and Dental Medicine at Johann Wolfgang Goethe-University, Frankfurt, Germany; ${ }^{2}$ Department of

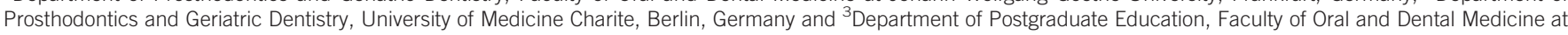
Johann Wolfgang Goethe-University, Frankfurt, Germany

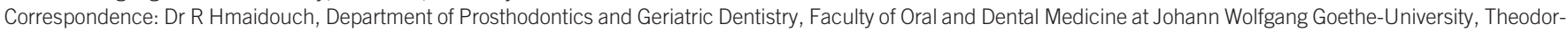
Stern-Kai 7, Building 29, Frankfurt 60596, Germany

E-mail: Hmaidouch@med.uni-frankfurt.de

Accepted 28 April 2014 
using different polishing techniques on the ceramic surface instead of glazing. ${ }^{21-23}$ The effects of various surface treatments on the surface properties of different yttria-stabilized tetragonal zirconia polycrystal (Y-TZP) ceramics has also been reported in previous in vitro studies. ${ }^{24-27}$

The effect of adjustments performed after luting ceramic restorations on the surface roughness is of clinical interest. Zirconia has not been studied with respect to roughness after clinically simulated grinding and polishing. Therefore, the aim of this study was to evaluate the effects of clinically simulated grinding and polishing on the surface roughness of $3 \%(n / n)$ Y-TZP ceramic for full-zirconia crowns and compare it with the roughness of conventionally veneered 3\% Y-TZP. The hypothesis of this study was that clinically simulated intraoral polishing of glazed full-contour zirconia (GFZ) provides smooth surfaces similar to those of untreated GFZ and to polished veneered fullcontour zirconia (VFZ) surfaces.

\section{MATERIALS AND METHODS}

Commercially available 3\% $(n / n) \mathrm{Y}_{2} \mathrm{O}_{3}$-stabilized $\mathrm{ZrO}_{2}$ (Zirluna' ACF Amberger Central Fraescenter, Amberg, Germany) was used. Thirty specimens were fabricated in the form of bars. Each specimen was cut from bulk (pre-sintered) blocks using $\left(100 \mathrm{r} \cdot \mathrm{min}^{-1}\right)$ a water-cooled diamond saw (Isomet; Buehler GmbH, Düsseldorf, Germany) and subsequently polished using 1200 and 4000 grit SiC paper with a microgrinding system (400CS; Exakt, Norderstedt, Germany) to obtain reproducible parallelepipeds. The specimens were sintered at $1530{ }^{\circ} \mathrm{C}$ for $2 \mathrm{~h}$ in a VITA Zyrcomat oven (Vita Zahnfabrik, Bad Saeckingen, Germany).

The specimens (30 $\mathrm{mm} \times 6 \mathrm{~mm} \times 2 \mathrm{~mm}$ ) were randomly divided into two groups $(n=15)$. Fifteen specimens (experimental, group 1) were glazed at $900{ }^{\circ} \mathrm{C}$ using Vita Glaze (Vita Zahnfabrik, Bad Saeckingen, Germany) without veneering, and the other 15 specimens (control, group 2) were veneered with an approximately $2 \mathrm{~mm}$ layer of feldspathic ceramic (VitaVM9; Vita Zahnfabrik, Bad Saeckingen, Germany) and then glazed using Vita Glaze at $900{ }^{\circ} \mathrm{C}$. The firing was performed using a Vita InCeramat (Vita Zahnfabrik, Bad Saeckingen, Germany) oven. The specimens were fixed in a profilometer (Perthometer SP5, Göttingen, Germany), and the maximum roughness depth $\left(R_{\max }\right.$ : the perpendicular distance between the highest peak and lowest valley of the roughness profile within the measurement line) values were measured, five measurements for each specimen, and a mean value was calculated. After obtaining the roughness measurements, the specimens were subjected to surface manipulations that are commonly performed in dental practice.

Grinding the specimens: the specimens were fixed in a stand to ensure that the orientation of the specimens was maintained throughout the grinding procedures. Thereafter, the specimens were ground under water coolant with NTI round-end cylinder-shaped diamond rotary cutting instruments series K881 (141)-016 F-FG (NTI-Kahla $\mathrm{GmbH}$, Kahla, Germany) mounted on a cutting/grinding turbine at $200000 \mathrm{r} \cdot \mathrm{min}^{-1}$ for $15 \mathrm{~s}$ and $2 \mathrm{~N}$ pressure realized with an apparatus that allowed independent control over the applied pressure, speed, and rotational velocity. Grinding was oriented along the length of the specimens. For grinding, diamond burs were used sequentially: red, with grit size of $20 \mu \mathrm{m}$, then a fine instrument (yellow) with grit size of $10 \mu \mathrm{m}$ and finally, an extra-fine instrument (white) with grit size of $7.5 \mu \mathrm{m}$. The grinding was performed with a continuous forward and backward sweeping movement similar to the clinical procedure. New diamond instruments were used for each specimen. After grinding with each instrument, the specimens were cleaned with acetone, then air dried and fixed in the profilometer to measure the $R_{\max }$ values; five measurements were obtained for each specimen after each grinding procedure.

Polishing of the specimens: the ground surfaces were polished with a handpiece for $15 \mathrm{~s}$ and with $2 \mathrm{~N}$ pressure. Polishing was performed using an NTI polishing kit (HP 802104; P341, P3401, P34001): coarse at $15000 \mathrm{r} \cdot \mathrm{min}^{-1}$, medium at $10000 \mathrm{r} \cdot \mathrm{min}^{-1}$ and fine at $5000 \mathrm{r} \cdot \mathrm{min}^{-1}$. The sweeping movements were in the same direction as during the grinding process. New polishing instruments were used for each specimen. After polishing with each instrument, the $R_{\max }$ values (five measurements for each specimen after each polishing procedure) were determined using the profilometer as described previously.

The effects of the polishing and grinding procedures on the surface roughness were evaluated by one-way analysis of variance (ANOVA) and compared by the Tukey honestly significant difference test $(\alpha=0.05)$ using OriginLab V. 7.5 (OriginLab, Northampton, MA, USA) for Windows statistical software.

On completion of the profilometric evaluation, representative specimens from each group and after each treatment step were prepared for scanning electron microscopy (SEM; FEI Quanta 600 FEG; FEI, Eindhoven, Netherlands). SEM images were acquired of each of these specimens at a magnification of $\times 500$.

\section{RESULTS}

A total of 525 measurements were recorded for each of the two groups. Table 1 shows the means and standard deviations obtained for the roughness for each ceramic in its as-glazed, ground and polished state.

\section{Influence of grinding}

The roughness of the specimens in both groups increased significantly after coarse grinding. Then, the roughness decreased significantly after medium and fine grinding only in group 1 (Figure 1). However, the roughness in group 2 was significantly decreased only after medium grinding, but after fine grinding, no significant difference was observed $(P=0.51)$ (Figure 2$)$.

Comparison between fine-ground and glazed surfaces: no significant difference $(P=0.19)$ was found between the roughness of fineground zirconia surfaces and the roughness of GFZ surfaces (Figure 1). However, the roughness of fine-ground veneered zirconia surfaces was significantly higher $(P=0.009)$ than the roughness of glazed veneered zirconia surfaces (Figure 2).

Table 1 Roughness of each ceramic in its as-glazed, ground and polished state

\begin{tabular}{|c|c|c|c|c|c|c|c|c|}
\hline \multirow[b]{2}{*}{ Group } & \multirow[b]{2}{*}{ Ceramic } & \multirow[b]{2}{*}{ Glazed } & \multicolumn{3}{|c|}{ Ground } & \multicolumn{3}{|c|}{ Polished } \\
\hline & & & Coarse & Medium & Fine & Coarse & Medium & Fine \\
\hline 1 & Y-TZP only glazed & $4.31 \pm 1.93$ & $12.57 \pm 4.40$ & $5.53 \pm 2.06$ & $3.76 \pm 1.02$ & $3.35 \pm 0.82$ & $2.96 \pm 0.59$ & $2.41 \pm 0.51$ \\
\hline 2 & Y-TZP/veneered with VM9 & $7.23 \pm 2.71$ & $24.13 \pm 4.53$ & $15.03 \pm 2.38$ & $13.51 \pm 2.55$ & $12.17 \pm 2.50$ & $10.24 \pm 2.02$ & $8.10 \pm 1.99$ \\
\hline
\end{tabular}

Y-TZP, yttria-stabilized tetragonal zirconia polycrystal. $R_{\max }$ in $\mu \mathrm{m}$. 


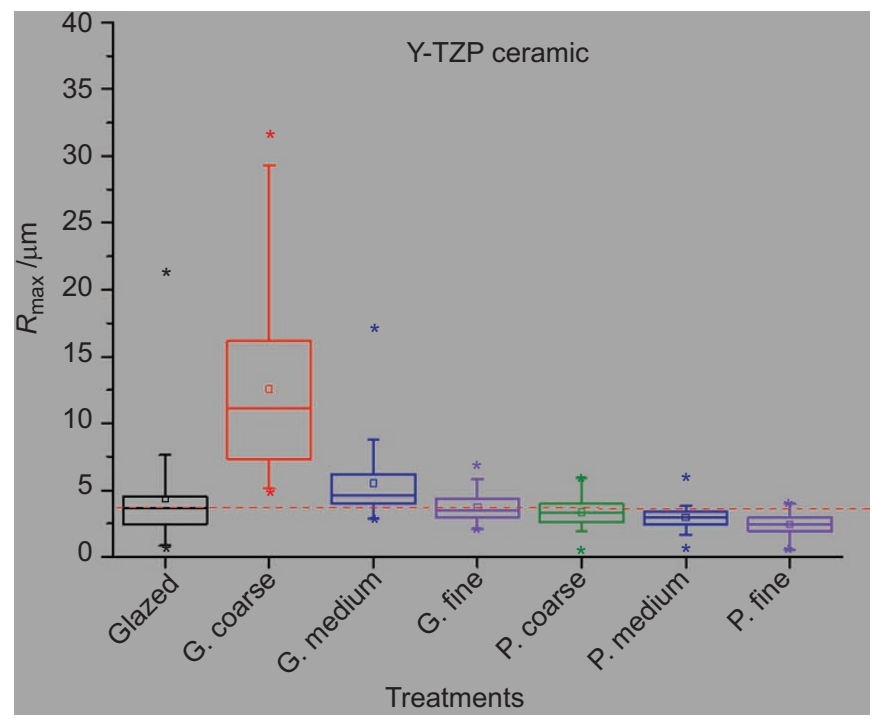

Figure 1 Roughness results for the non-veneered Y-TZP. G, ground; P, polished. Y-TZP, yttria-stabilized tetragonal zirconia polycrystal.

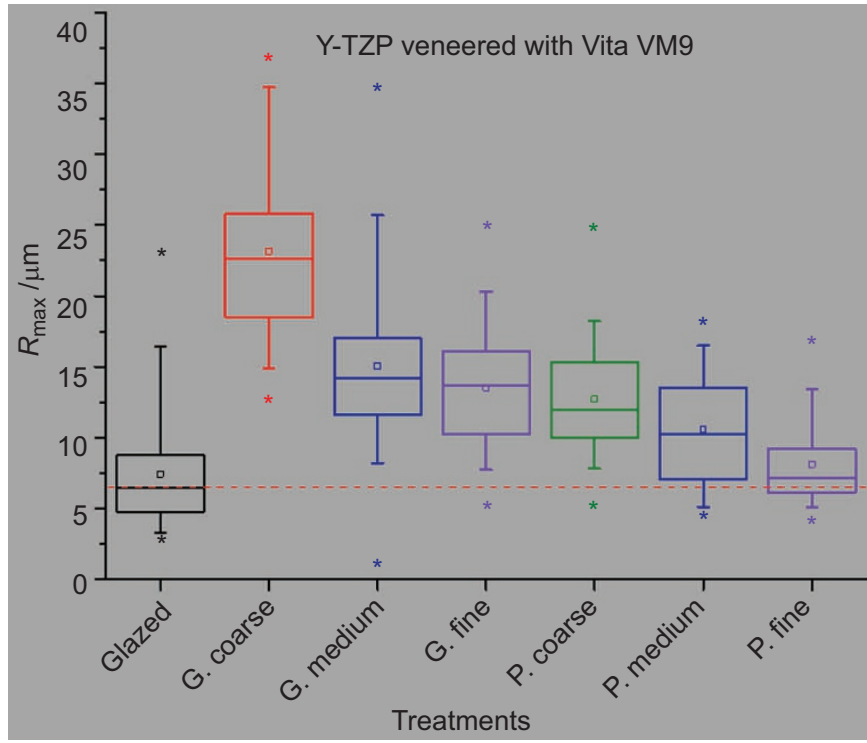

Figure 2 Roughness results for the veneered Y-TZP. G, ground; P, polished. Y-TZP, yttria-stabilized tetragonal zirconia polycrystal.

\section{Influence of polishing}

No statistically significant differences were found between the roughness of coarse-polished specimens and roughness of fine-ground specimens for both non-veneered $(P=0.54)$ and veneered zirconia $(P=0.99)$, but through medium and fine polishing, the roughness was significantly reduced in both groups (Figures 1 and 2).

Comparison between fine-polished and glazed surfaces: no significant difference $(P=0.45)$ was found between the roughness of fine polished full-contour zirconia specimens and the roughness of GFZ.

However, after fine polishing, the veneered ceramic specimens showed significantly higher $R_{\max }$ comparing to their as-glazed state $(P=0.32)$.

Comparison between group 1 and group 2: according to the one-way ANOVA results, ceramic specimens in group 1 showed significantly

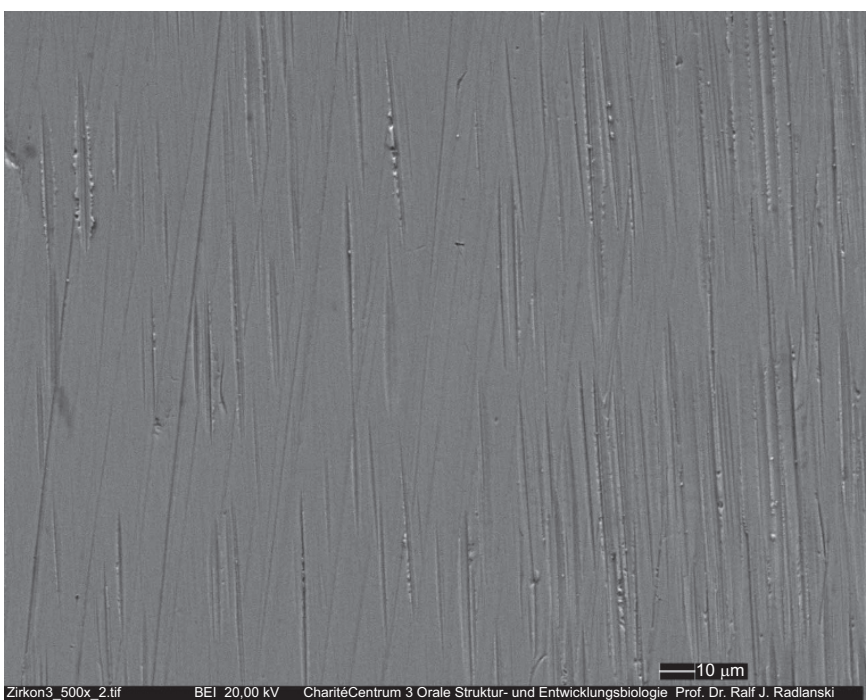

Figure 3 SEM image of zirconia sample ground with the coarse diamond instrument. Original magnification $\times 500$. SEM, scanning electron microscopy.

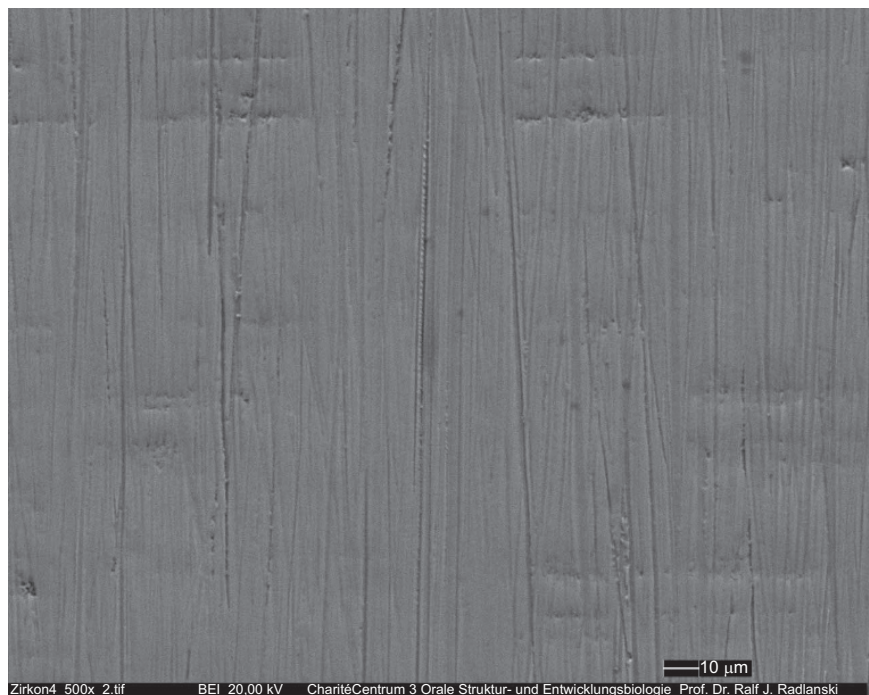

Figure 4 SEM image of zirconia sample ground with the three diamond instruments and then polished using the coarse polisher. Original magnification $\times 500$. Grooves could be reduced even further. SEM, scanning electron microscopy.

lower surface roughness $(P<0.05)$ than the ceramic specimens in group 2 after glazing, grinding and polishing procedures.

Analysis of the different ceramic surface treatments by scanning electron microscopy (SEM) provided valuable information about the resulting topography. The ground surfaces of FZ using the coarse red diamond instrument (Figure 3) showed grooves that were reduced after using the following two grinding instruments (medium and fine) and after using the coarse polisher (Figure 4). After completing the polishing, the grooves were significantly reduced (Figure 5).

Porcelain surfaces ground with coarse diamond burs show ridges and grooves (Figure 6); moreover, many voids appear due to incomplete condensation. After polishing, the condensation defects remain but have been smoothed and slightly rounded; the voids from the porosities 


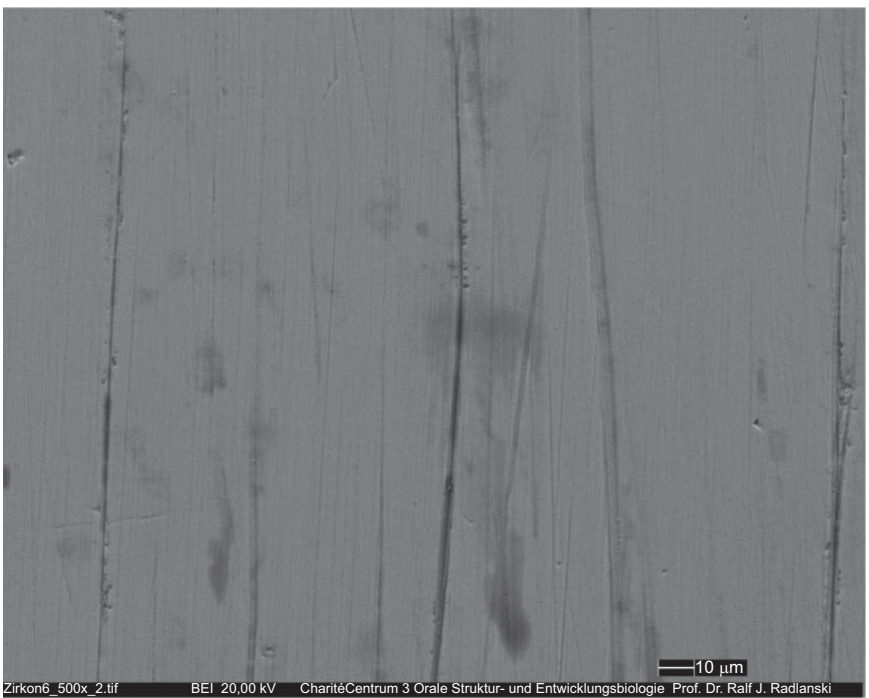

Figure 5 SEM image of zirconia sample ground with the three diamond instruments and then polished with the three polishers. Original magnification $\times 500$. SEM, scanning electron microscopy.

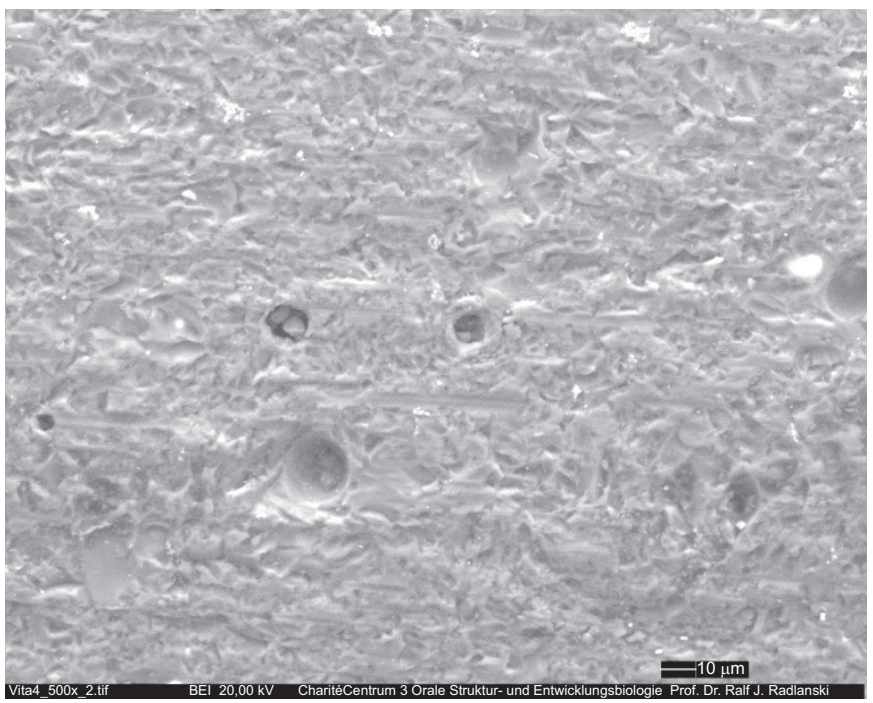

Figure 7 SEM image of porcelain sample ground with the three diamond instruments and then polished using the coarse polisher. Original magnification $\times 500$. SEM, scanning electron microscopy.

appear shallower (Figure 7). Traces of ridges and grooves did not disappear after polishing was completed; however, the polished side contained pitted areas with numerous surface irregularities (Figure 8).

\section{DISCUSSION}

The hypothesis of this study was accepted because the clinically simulated intraoral polishing of non-veneered GFZ provides similarly smoothened surfaces to those of the glazed, untreated (FZ) and to the polished veneered zirconia.

The results showed that the roughness was strongly material-dependent, which is in agreement with the findings of previous studies. ${ }^{28-29}$ Lower roughness of non-veneered zirconia specimens than that of veneered zirconia (VFZ) specimens was observed after each treatment

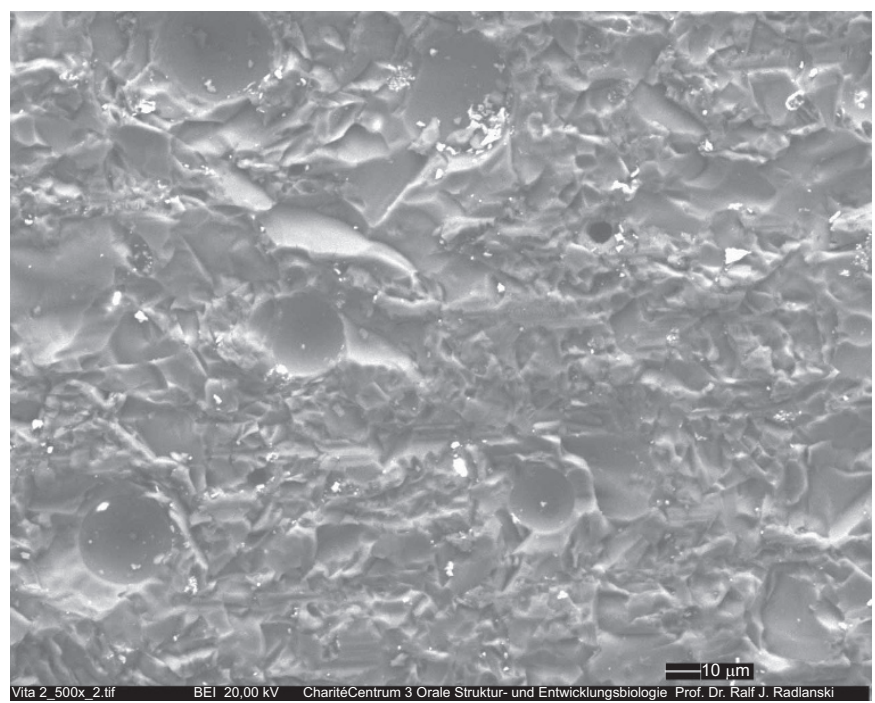

Figure 6 SEM image of representative sample of porcelain ground with the coarse diamond instrument. Original magnification $\times 500$. The surface reveals a maze of steep ridges, grooves and voids. SEM, scanning electron microscopy.

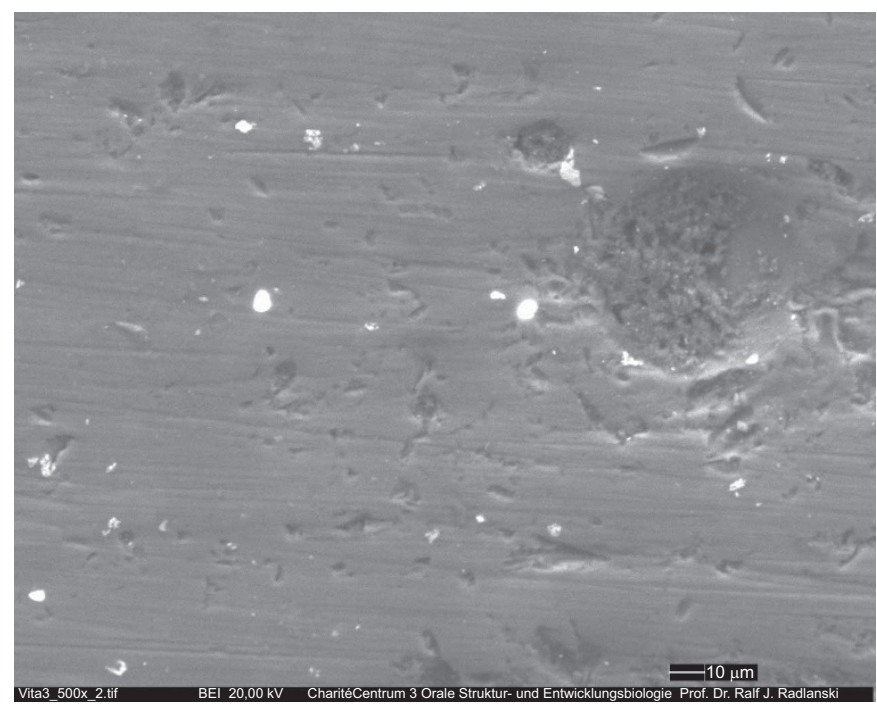

Figure 8 SEM image of porcelain sample ground with the three diamond instruments and then polished with the three polishers. Original magnification $\times 500$. SEM, scanning electron microscopy.

procedure. This difference can be explained by the different compositions. SEM investigation of the treated surfaces showed that defects on the veneered surfaces caused by grinding were deeper than those on the zirconia surfaces, which led to the higher roughness values (Figures 3 and 6).

Proper polishing of ceramic restorations was considered as an important step because it was previously reported that increased surface roughness associated with improper polishing can increase the wear rate of the opposing teeth and can also compromise the clinical performance of the restoration. ${ }^{19,30-31}$ The polishability of dental ceramics is normally tested in vitro on flat specimens for certain times and rotation speeds. ${ }^{28,32}$ Typically, the press-on force is not controlled during polishing procedures; this issue is not even mentioned in most 
studies. ${ }^{21,29}$ In this study, a press-on force of $2 \mathrm{~N}$ was applied during each grinding and polishing step for $15 \mathrm{~s}$, which ensured identical treatment for all specimens. In this study, grinding conditions under water coolant provided lower temperatures, which have a better influence on the $\mathrm{m} \rightarrow \mathrm{t}$ phase transformation of $3 \% \mathrm{Y}$-TZP than dry grinding. ${ }^{26}$

To simulate clinical conditions in this study, surfaces of both zirconia and porcelain were investigated after glazing, grinding and polishing using diamond rotary cutting and polishing instruments.

Grinding with a diamond burr caused significant changes in surface roughness values; as expected, the surface roughness of both ceramics was significantly increased after coarse grinding. These results are similar to those reported by other investigators. ${ }^{28,33}$ Curtis et al. reported that the surface roughness of $3 \%$ Y-TZP increased as a result of surface grinding after wet and dry grinding. ${ }^{33}$

After medium and fine grinding, the roughness of GFZ was significantly reduced, but no significant differences were found between the roughness after fine grinding (pre-polishing) and the roughness after coarse polishing (Figures 1, 4 and 5). We recognize that fine grinding of GFZ provides similar smoothness to that of coarse-polished FZ, and therefore, it might consequently be suggested that grinding using this three-step system is sufficient and may enable dentists to abstain from subsequent polishing procedures. Further investigations of this issue should be conducted to answer the question of whether fine grinding using this three-step grinding system is adequate.

However, medium and fine polishing could significantly reduce the roughness of the investigated FZ surfaces, possibly by removing weakly attached surface grains and by eliminating the grinding trace lines (Figures 1 and 5). No significant difference was found between the roughness of fine-polished FZ and the roughness of GFZ, which confirm the hypothesis of this study that clinically simulated intraoral polishing of GFZ provides smooth surfaces similar to those of untreated GFZ. The roughness of the VFZ surfaces was not significantly reduced after either fine grinding or coarse polishing, which can be explained by the deep defects (grooves) caused by coarse grinding (Figures 6 and 7). These defects could not be completely flattened or removed, thereby explaining the higher roughness of VFZ specimens compared with the fine-ground and coarse-polished FZ specimens, which did not acquire deep defects after coarse grinding because of their higher strength.

The most interesting finding of this study was that there was no significant difference $(P=0.49)$ between the roughness of fine-ground FZ specimens $((2.41 \pm 0.51) \mu \mathrm{m})$ and the roughness of glazed FZ surfaces $((4.31 \pm 1.93) \mu \mathrm{m})$, which can be explained by the very small bubbles within the glazing layer. Previous studies on the roughness of zirconia after grinding and polishing are few, but in a study using a commercial Soflex polishing system (3M-ESPE, Neuss, Germany), significant reduction in the surface roughness of zirconia was confirmed after polishing compared to the surface roughness after grinding. ${ }^{28}$ There were no studies identified by the authors that investigated surface roughness $\left(R_{\max }\right)$ after clinically simulated grinding and polishing of the ceramic materials studied here; therefore, no further comparisons can be made with the results reported in earlier studies.

As expected, the roughness values of the polished samples were improved, which was reflected in the suggestion that polishing may have been effective in favouring the flaw distribution. This would support the hypothesis that polishing is able to remove some of the grinding-induced defects, although it also generates flaws that have more favourable distribution.

The polishing protocol used in this study can be useful in determining the appropriate polishing parameters for each polishing system of interest. Therefore, the results of this study can only predict the results of polishing when the described polishing protocol is used.

For the reduction of tooth wear and for the reduction of subcritical crack growth, polishing the ceramic surface may therefore be required on occasion.

\section{CONCLUSION}

Grinding the GFZ using the NTI three-step system could deliver smooth surfaces comparable to those of untreated GFZ. Less roughened surfaces, fewer defects and lower roughness values resulted after grinding and polishing FZ than VFZ. Less roughness could be achieved with polishing FZ when compared to GFZ.

\section{ACKNOWLEDGEMENTS}

The authors thank Forschungsgemeinschaft Dental e.V. for supporting this study (project no. 3/2012).

1 Sundh A, Sjögren G. Fracture resistance of all-ceramic zirconia bridges with differing phase stabilizers and quality of sintering. Dent Mater 2006; 22(8): 778-784.

2 Guazzato M, Albakry M, Quach L et al. Influence of surface and heat treatments on the flexural strength of a glass-infiltrated alumina/zirconia-reinforced dental ceramic. Dent Mater 2005; 21(5): 454-463.

3 Aboushelib MN, de Jager N, Kleverlaan CJ et al. Microtensile bond strength of different components of core veneered all-ceramic restorations. Dent Mater 2005; 21(10): 984-991.

4 Raigrodski AJ, Yu A, Chiche GJ et al. Clinical efficacy of veneered zirconium dioxidebased posterior partial fixed dental prostheses: five-year results. J Prosthet Dent 2012; 108(4): 214-222.

5 Kokubo Y, Tsumita M, Sakurai S et al. Five-year clinical evaluation of In-Ceram crowns fabricated using GN-I (CAD/CAM) system. J Oral Rehabil 2011; 38(8): 601-607.

6 Ortorp A, Kihl ML, Carlsson GE. A 3-year retrospective and clinical follow-up study of zirconia single crowns performed in a private practice. J Dent 2009; 37(9): 731-736.

7 Etman MK, Woolford MJ. Three-year clinical evaluation of two ceramic crown systems: a preliminary study. J Prosthet Dent 2010; 103(2): 80-90.

8 Bindl A, Mörmann WH. Survival rate of mono-ceramic and ceramic-core CAD/CAMgenerated anterior crowns over 2-5 years. Eur J Oral Sci 2004; 112(2): 197-204.

9 Bindl A, Lüthy H, Mörmann WH. Strength and fracture pattern of monolithic CAD/ CAM-generated posterior crowns. Dent Mater 2006; 22(1): 29-36.

10 Sorensen JA, Cruz M, Mito WT et al. A clinical investigation on three-unit fixed partial dentures fabricated with a lithium disilicate glass-ceramic. Pract Periodontics Aesthet Dent 1999; 11(1): 95-106; quiz 108

11 Sorensen JA, Choi C, Fanuscu MI et al. IPS Empress crown system: three-year clinical trial results. J Calif Dent Assoc 1998; 26(2): 130-136.

12 Tinschert J, Natt G, Mautsch W et al. Fracture resistance of lithium disilicate-, alumina-, and zirconia-based three-unit fixed partial dentures: a laboratory study. Int J Prosthodont 2001; 14(3): 231-238.

13 Rosentritt M, Preis V, Behr M et al. Two-body wear of dental porcelain and substructure oxide ceramics. Clin Oral Investig 2012; 16(3): 935-943.

14 Brewer JD, Garlapo DA, Chipps EA et al. Clinical discrimination between autoglazed and polished porcelain surfaces. J Prosthet Dent 1990; 64(6): 631-634.

15 Reis AF, Giannini M, Lovadino JR et al. Effects of various finishing systems on the surface roughness and staining susceptibility of packable composite resins. Dent Mater 2003; 19(1): 12-18.

16 Monasky GE, Taylor DF. Studies on the wear of porcelain, enamel, and gold. J Prosthet Dent 1971; 25(3): 299-306.

17 Guazzato M, Albakry M, Quach L et al. Influence of surface and heat treatments on the flexural strength of a glass-infiltrated alumina/zirconia-reinforced dental ceramic. Dent Mater 2005; 21(5): 454-463.

18 Williamson RT, Kovarik RE, Mitchell RJ. Effects of grinding, polishing, and overglazing on the flexure strength of a high-leucite feldspathic porcelain. Int J Prosthodont 1996; 9(1): 30-37.

19 Bollen CM, Lambrechts P, Quirynen M. Comparison of surface roughness of oral hard materials to the threshold surface roughness for bacterial plaque retention: a review of the literature. Dent Mater 1997; 13(4): 258-269.

20 Campbell SD. Evaluation of surface roughness and polishing techniques for new ceramic materials. J Prosthet Dent 1989; 61(5): 563-568.

21 Wright MD, Masri R, Driscoll CF et al. Comparison of three systems for the polishing of an ultra-low fusing dental porcelain. J Prosthet Dent 2004; 92(5): 486-490.

22 Patterson CJ, McLundie AC, Stirrups DR et al. Efficacy of a porcelain refinishing system in restoring surface finish after grinding with fine and extra-fine diamond burs. J Prosthet Dent 1992; 68(3): 402-406.

23 Raimondo RL Jr, Richardson JT, Wiedner B. Polished versus autoglazed dental porcelain. J Prosthet Dent 1990; 64(5): 553-557. 
24 de Kler M, de Jager N, Meegdes M et al. Influence of thermal expansion mismatch and fatigue loading on phase changes in porcelain veneered Y-TZP zirconia discs. J Oral Rehabil 2007; 34(11): 841-847.

25 Kosmac T, Oblak C, Jevnikar P et al. Strength and reliability of surface treated Y-TZP dental ceramics. J Biomed Mater Res 2000; 53(4): 304-313.

26 Luthardt RG, Holzhüter M, Sandkuhl 0 et al. Reliability and properties of ground Y-TZP-zirconia ceramics. J Dent Res 2002; 81(7): 487-491.

27 Wang $\mathrm{H}$, Aboushelib MN, Feilzer AJ. Strength influencing variables on CAD/CAM zirconia frameworks. Dent Mater 2008; 24(5): 633-638.

28 Kou W, Molin M, Sjögren G. Surface roughness of five different dental ceramic core materials after grinding and polishing. J Oral Rehabil 2006; 33(2): 117-124.

29 Sarikaya I, Güler AU. Effects of different polishing techniques on the surface roughness of dental porcelains. J App/ Oral Sci 2010; 18(1): 10-16.

30 al-Hiyasat AS, Saunders WP, Sharkey SW et al. Investigation of human enamel wear against four dental ceramics and gold. J Dent 1998; 26(5/6): 487-495.
31 Magne $\mathrm{P}, \mathrm{Oh}$ WS, Pintado MR et al. Wear of enamel and veneering ceramics after laboratory and chairside finishing procedures. J Prosthet Dent 1999; 82(6): 669-679. 32 Subaşı MG, İnan Ö. Evaluation of the topographical surface changes and roughness of zirconia after different surface treatments. Lasers Med Sci 2012; 27(4): 735-742.

33 Curtis AR, Wright AJ, Fleming GJ. The influence of surface modification techniques on the performance of a Y-TZP dental ceramic. J Dent 2006; 34(3): 195-206.

This work is licensed under a Creative Commons Attribution-

NonCommercial-ShareAlike 3.0 Unported License. The images or other third party material in this article are included in the article's Creative Commons license, unless indicated otherwise in the credit line; if the material is not included under the Creative Commons license, users will need to obtain permission from the license holder to reproduce the material. To view a copy of this license, visit http://creativecommons.org/licenses/by-nc-sa/3.0/ 